\title{
Article \\ Estimation of the Mechanical Parameters for a Reduced Coupled Flexural-Torsional Beam Model of a Tall Building by a Sub-Structure Approach
}

\author{
Federico Cluni (D), Stefano Fiorucci, Vittorio Gusella (D) and Massimiliano Gioffrè *(D) \\ Department of Civil and Environmental Engineering, University of Perugia, Via G. Duranti 93, \\ 06125 Perugia, Italy; federico.cluni@unipg.it (F.C.); stefano.fiorucci@virgilio.it (S.F.); \\ vittorio.gusella@unipg.it (V.G.) \\ * Correspondence: massimiliano.gioffre@unipg.it; Tel.: +39-075-585-3902 \\ + All authors contributed equally to this work.
}

check for updates

Citation: Cluni, F.; Fiorucci, S.; Gusella, V.; Gioffrè, M. Estimation of the Mechanical Parameters for a Reduced Coupled Flexural-Torsional Beam Model of a Tall Building by a Sub-Structure Approach. Appl. Sci. 2021, 11, 4655. https://doi.org/ 10.3390/app11104655

Academic Editors: Angelo Luongo and Daniele Zulli

Received: 16 April 2021

Accepted: 15 May 2021

Published: 19 May 2021

Publisher's Note: MDPI stays neutral with regard to jurisdictional claims in published maps and institutional affiliations.

Copyright: (c) 2021 by the authors. Licensee MDPI, Basel, Switzerland. This article is an open access article distributed under the terms and conditions of the Creative Commons Attribution (CC BY) license (https:/ / creativecommons.org/licenses/by/ $4.0 /)$.

\begin{abstract}
The use of equivalent beam models to estimate the dynamical characteristics of complex tall buildings has been investigated by several authors. The main reason is the structural response estimation to stochastic loads, such as wind and earthquake, using a reduced number of degrees of freedom, which reduces the computational costs and therefore gives the designer an effective tool to explore a number of possible structural solutions. In this paper, a novel approach to calibrate the mechanical and dynamical features of a complete 3D Timoshenko beam, i.e., describing bending, shear and torsional behavior, is proposed. This approach is based on explicitly considering the sub-structures of the tall building. In particular, the frames, shear walls and lattice sub-systems are modeled as equivalent beams, constrained by means of rigid diaphragms at different floors. The overall dynamic features of the tall building are obtained by equating the deformation energy of an equivalent sandwich beam with that of the selected sub-structures. Finally, the 3D Timoshenko equivalent beam parameters are calibrated by minimizing a suitable function of modal natural frequencies and static displacements. The closed form modal solution of the equivalent beam model is used to obtain the response to stochastic loads.
\end{abstract}

Keywords: tall buildings; Timoshenko beam; reduced-order models; environmental loads; stochastic dynamics

\section{Introduction}

In the last five decades, the reduction of complex structural systems to equivalent beam models has been investigated by several authors. The availability of simple models that can accurately describe the global response is appealing because it can reduce the time and computational costs required by detailed numerical finite element (FE) models with a large number of degree of freedom [1] and simplify the structural analysis increasing both the efficiency and understanding of the system behavior. This aspect becomes crucial when designing complex tall buildings with irregular shapes that have been built around the world in the last decades.

Indeed, the development of structural optimization algorithms capable of reducing the cost of such buildings while maintaining appropriate safety levels might be timeconsuming and even not feasible with a large-dimension problem that could require special techniques. For this reason, reliability-based design optimization (RBDO) has been proposed as a framework to obtain minimum building costs constrained to prescribed safety levels. In particular, Spence and Gioffrè proposed an RBDO algorithm for member size optimization based on the definition of explicit sub-problems driven by safety constraints on both global and local structural response to stochastic wind load and with uncertain mechanical parameters [2-4]. 
The development of reduced-order models is also crucial for improving the effectiveness of preliminary sensitivity analysis in which the influence of random loads and uncertain mechanical parameters on the linear and nonlinear structural response is of interest $[5,6]$.

For all these reasons, a number of reduced-order equivalent beam models have been proposed in the literature, where a combination of in-series and/or in-parallel bending, shear and torsional stiffnesses are considered to model the typical tall building bracing resisting systems (e.g., walls, frames, lattice structures, frames, coupled shear walls). Appendix A reports a detailed summary of the main contributions to the literature about this topic. Recent papers on equivalent beam models [7-10] testify that there is still interest in finding effective solutions to find reduced-order systems to describe complex structures.

One of the issues is related to the effective calibration of the equivalent beam mechanical and dynamical parameters. For example, the equivalent 3D Timoshenko beam model calibration proposed in [8] was based on the availability of a detailed tall building FE model. A possible drawback of this approach is that the detailed numerical modeling of complex tall buildings can be a time-consuming activity. On the other hand, the approach first proposed by Potzta and Kollar in [11] is appealing, since the equivalent beam parameters are directly obtained by the stiffness features of each of the different horizontal load-resisting sub-structures. The drawback of this method is that the equivalent beam parameters are different for each considered mode shape. Dynamic analysis by modal superposition is therefore dependent on the load frequency content and preliminary estimation of the number of modes to be considered is required. Furthermore, direct time integration of the dynamic system equations is not possible.

This paper proposes a novel two-step calibration procedure to merge the advantages of each of the two approaches described above and to overtake their drawbacks. First, the equivalent sandwich beam parameters of a tall building are evaluated with the approach proposed in [11] (e-SBM) for a chosen number of mode shapes, avoiding the time consuming detailed FE modeling. Second, the equivalent Timoshenko beam model (e-TBM) described in [8] is calibrated using a suitable optimization procedure aimed to target the e-SBM beam response in terms of modal natural frequencies and static displacements. The obtained e-TBM has the advantage of having a closed-form solution of all the natural frequencies and mode shapes that can be effectively used to estimate the response to dynamic random loads by modal superposition and/or direct time integration.

The structure of the paper is as follows. First, the e-TBM and the e-SBM beam main features are briefly recalled and the optimization-based calibration strategy is described. Second, a case study is used to demonstrate the proposed novel approach effectiveness.

\section{The Novel Equivalent Beam Model Calibration}

\subsection{The Timoshenko Beam with De Saint-Venant Torsional Behavior (e-TBM)}

The equivalent beam model presented in [8] to estimate the three-dimensional response of asymmetric tall buildings was based on the Timoshenko beam with coupled De Saint-Venant torsional behavior (e-TBM). As it is well known, the Timoshenko beam model enhances the Euler-Bernoulli beam model by considering the shear stiffness, the crosssection rotation inertia and the possibility to have deformation where the beam axis can also be not normal to the cross section.

In this Section the ruling equations are briefly recalled and additional details can be found in [8]. Assuming a reference system where $z$ is the beam axis, $x$ and $y$ are the cross-section principal axis, the problem in the planar case, $y-z$, can be described by the following equations: 
- the balance equations

$$
\begin{aligned}
& \frac{d M_{x}}{d z}=V_{y}(z)-m_{x}(z) \\
& \frac{d V_{y}}{d z}=-q_{y}(z),
\end{aligned}
$$

where $q_{y}(z)$ and $m_{x}(z), V_{y}(z)$ and $M_{x}(z)$ are the distributed load and moment, the shear and the bending moment, respectively.

- the constitutive equations

$$
\begin{aligned}
M_{x} & =E I_{x} \frac{d \theta_{x}}{d z} \\
V_{y} & =G K_{y} \gamma_{y},
\end{aligned}
$$

where $d \theta_{x} / d z, \gamma_{y}, E I_{x}$ and $G K_{y}$ are curvature, shear deformation, bending stiffness and shear stiffness, respectively.

- the compatibility equation, assumed as in Timoshenko (1921)

$$
\frac{d u_{y}}{d z}=\gamma_{y}-\theta_{x} .
$$

Assuming constant stifnesses along the beam axis, the following equations are obtained

$$
\begin{aligned}
& G K_{y}\left(\frac{d^{2} u_{y}}{d z^{2}}+\frac{d \theta_{x}}{d z}\right)+q_{y}=0 \\
& E I_{x} \frac{d^{2} \theta_{x}}{d z^{2}}-G K_{y}\left(\frac{d u_{y}}{d z}+\theta_{x}\right)+m_{x}=0,
\end{aligned}
$$

which can be extended to the equations of motion assuming inertial forces and moments per unit length and $\mathrm{D}^{\prime}$ Alembert's principle

$$
\begin{aligned}
& G K_{y}\left(\frac{\partial^{2} u_{y}}{\partial t^{2}}+\frac{\partial \theta_{x}}{\partial z}\right)+q_{y}-\rho A \frac{\partial^{2} u_{y}}{\partial t^{2}}=0 \\
& E I_{x} \frac{\partial^{2} \theta_{x}}{\partial z^{2}}-G K_{y}\left(\frac{\partial u_{y}}{\partial z}+\theta_{x}\right)+m_{x}-\rho I_{x} \frac{\partial^{2} \theta_{x}}{\partial t^{2}}=0
\end{aligned}
$$

where $\rho$ is the mass density, assumed to be uniform over both the beam cross-section area and beam length.

The previous planar model can be easily extended to the 3D case writing the equations of motion in the $x-z$ plane and describing the torsional deformation by the classical De-Saint Venant's model where, assuming the torsional moment, $M_{t}$, stiffness, $G J_{t}$, and distributed moment, $m_{z}$, and using the constitutive equation

$$
M_{t}=G J_{t} \frac{d \phi}{d z},
$$

and the balance equation

$$
\frac{d M_{t}}{d z}=-m_{z}
$$

one obtains

$$
G J_{t} \frac{d^{2} \phi}{d z^{2}}+m_{z}=0 .
$$


Finally, assuming uniform mass density $\rho$ and using D'Alembert's principle, the equation of motion becomes

$$
G J_{t} \frac{\partial^{2} \phi}{\partial z^{2}}+m_{z}-\rho I_{0} \frac{\partial^{2} \phi}{\partial t^{2}}=0
$$

where $I_{0}=\int_{\Omega}\left(x^{2}+y^{2}\right) d \Omega$ is the polar moment of inertia and $\Omega$ is the cross section surface.

The equations ruling the $3 \mathrm{D}$ dynamic problem can be obtained by coupling the Timoshenko beam model in the $x$ and $y$ directions with the torsional model in (13) and assuming a reference system with the origin in the cross-section centroid

$$
\begin{aligned}
& G K_{x}\left(\frac{\partial^{2} u_{x}}{\partial z^{2}}-\frac{\partial \theta_{y}}{\partial z}\right)-M \frac{\partial^{2} u_{x}}{\partial t^{2}}-M y_{S} \frac{\partial^{2} \phi}{\partial t^{2}}+S_{x}^{M} \frac{\partial^{2} \phi}{\partial t^{2}}+q_{x}=0 \\
& E I_{y} \frac{\partial^{2} \theta_{y}}{\partial z^{2}}+G K_{x}\left(\frac{\partial u_{x}}{\partial z}-\theta_{y}\right)+I_{y}^{M} \frac{\partial^{2} \theta_{y}}{\partial t^{2}}-I_{x y}^{M} \frac{\partial^{2} \theta_{x}}{\partial t^{2}}+m_{y}=0 \\
& G K_{y}\left(\frac{\partial^{2} u_{y}}{\partial z^{2}}+\frac{\partial \theta_{x}}{\partial z}\right)-M \frac{\partial^{2} u_{y}}{\partial t^{2}}+M x_{S} \frac{\partial^{2} \phi}{\partial t^{2}}-S_{y}^{M} \frac{\partial^{2} \phi}{\partial t^{2}}+q_{y}=0 \\
& E I_{x} \frac{\partial^{2} \theta_{x}}{\partial z^{2}}-G K_{y}\left(\frac{\partial u_{y}}{\partial z}+\theta_{x}\right)-I_{x}^{M} \frac{\partial^{2} \theta_{x}}{\partial t^{2}}+I_{x y}^{M} \frac{\partial^{2} \theta_{y}}{\partial t^{2}}+m_{x}=0 \\
& G J \frac{\partial^{2} \phi}{\partial z^{2}}-M y_{S} \frac{\partial^{2} u_{x}}{\partial t^{2}}+M x_{S} \frac{\partial^{2} u_{y}}{\partial t^{2}}-I_{S} \frac{\partial^{2} \phi}{\partial t^{2}}+S_{x}^{M} \frac{\partial^{2} u_{x}}{\partial t^{2}}-S_{y}^{M} \frac{\partial^{2} u_{y}}{\partial t^{2}}+ \\
& +2\left(x_{S} S_{y}^{M}+y_{S} S_{x}^{M}\right) \frac{\partial^{2} \phi}{\partial t^{2}}+m_{z}+q_{x} y_{S}-q_{y} x_{S}=0
\end{aligned}
$$

where

$$
\begin{gathered}
M=\int_{\Omega} \rho d \Omega, \quad S_{x}^{M}=\int_{\Omega} \rho y d \Omega, \quad S_{y}^{M}=\int_{\Omega} \rho x d \Omega \\
I_{x}^{M}=\int_{\Omega} \rho y^{2} d \Omega, \quad I_{y}^{M}=\int_{\Omega} \rho x^{2} d \Omega, \quad I_{x y}^{M}=\int_{\Omega} \rho x y d \Omega \\
I_{S}=M\left(x_{S}^{2}+y_{S}^{2}\right)+\left(I_{x}^{M}+I_{y}^{M}\right),
\end{gathered}
$$

with $S_{x}^{M}, S_{y}^{M}, I_{x}^{M}, I_{y}^{M}$ and $I_{x y}^{M}$ being the classical first and second inertia moments and $x_{S}$ and $y_{S}$ are the coordinates of the shear centre. Equations (14)-(18) can be used to compute natural frequencies and the corresponding mode shapes [8].

\subsection{The Sub-Structure Approach (e-SBM)}

The equivalent beam model proposed by Potzta and Kollar [11] is based on the substructure approach, which uses an equivalent cantilever sandwich beam to model the lateral load-resisting system of a tall building starting from the stiffnesses of the different structural sub-systems (e-SBM). The equivalent sandwich beam is given by coupling one Timoshenko beam with bending stiffness, $D_{0}$, and shear stiffness, $S$, and one Euler-Bernoulli beam with bending stiffness, $D_{l}$, assuming to have the same horizontal displacements at all levels. The parameter $D_{l}$ is also referred to as "local" stiffness since it is obtained from each of the subsystem columns and beams. Moreover, the 3D behavior is also described using the Vlasov non-uniform torsion theory. In this Section, the main features of the model described in [11] that will be used to develop the proposed novel equivalent beam model are recalled.

In the sub-structure approach, each lateral load-resisting sub-system of the building (i.e., wall, truss, frame, coupled shear wall) is replaced by a sandwich beam or a Timoshenko beam with suitable stiffness parameters. In this paper, a tall building with two sub-systems, frame and truss, will be considered. For these two cases, Table 1 in [11] gives the following stifness values: 
- $k$-th frame with $n+1$ columns, having cross section area, $A_{c i}$, and inertia, $I_{c i}, i=0, \ldots, n$, and $n$ beams having cross section inertia, $I_{b i}, i=1, \ldots, n$ :

$$
\begin{aligned}
D_{l k} & =\sum_{i=0}^{n} E I_{c i} \\
D_{0 k} & =\sum_{i=0}^{n} E A_{c i} c_{i}^{2} \\
S_{k} & =\left(S_{b}^{-1}+S_{c}^{-1}\right)^{-1} \\
S_{b} & =\sum_{i=1}^{n} \frac{12 E I_{b i}}{l_{i} h} \\
S_{c} & =\sum_{i=0}^{n} \frac{12 E I_{c i}}{h^{2}}
\end{aligned}
$$

where $c_{i}$ is the distance of the $i$-th column from the frame axis, $l_{i}$ is the span of the $i$-th beam (i.e., distance between columns $i$ and $i-1$ ) and $h$ is the constant inter-storey height. It is worth noting that these values do not depend on the number of floors.

- $\quad k$-th truss with columns and bracing having cross section area, $A_{c}$ and $A_{d}$, respectively:

$$
\begin{aligned}
D_{0 k} & =\frac{1}{2} E A_{c} L^{2} \\
S_{k} & =\frac{2 E h L^{2} A_{d}}{d^{3}}
\end{aligned}
$$

where $L$ is the span of the truss, $h$ is the inter-storey height and $d$ is the length of each of the two cross-bracing at each storey, with $d=\sqrt{L^{2}+h^{2}}$. In this case, a pure Timoshenko beam is assumed, since $D_{l}$ is null.

In the general 3D case, the tall building equivalent sandwich beam parameters can be found by using the approach based on the deformation energy and can be collected into three matrices, $\left[D_{0}\right],\left[D_{l}\right]$ and $[S]$. In the following, adopting the assumptions in [11], the reference system $x, y, z$ is used with the beam axis in the $x$ direction; $v$ and $w$ are the displacements of the beam axis in the $y$ and $z$ directions, while $\psi, \chi_{y}, \chi_{z}$ are the rotations about the $x, y$, and $z$ axis, respectively. Finally, $\gamma_{y}$ and $\gamma_{z}$ are the shear deformations, while

$$
\psi^{\prime}=\theta_{B}+\theta_{S},
$$

is the torsional deformation with the two components, $\theta_{B}$ and $\theta_{S}$, due to bending and shear of the single sub-structures, respectively. In the approach proposed in $[12,13]$ the following equations hold

$$
\begin{aligned}
v^{\prime} & =\chi_{y}+\gamma_{y} \\
w^{\prime} & =\chi_{z}+\gamma_{z} \\
\psi^{\prime} & =\theta_{S}+\theta_{B} .
\end{aligned}
$$

It is worth noting that neglecting the shear deformation, i.e., $\gamma_{y}=\gamma_{z}=\theta_{S}=0$ one obtains the standard Vlasov model with $v^{\prime}=\chi_{y}, w^{\prime}=\chi_{z}$ and $\psi^{\prime}=\theta_{B}$.

The values of $[S],\left[D_{0}\right]$ and $\left[D_{l}\right]$ are obtained assuming that the deformation energy of the tall building equivalent sandwich beam is the same of the sum of the deformation energy of all the $N$ sub-structures

$$
\begin{array}{r}
\frac{1}{2} \int\left(\left\{u^{\prime \prime}\right\}^{T}\left[D_{l}\right]\left\{u^{\prime \prime}\right\}+\{\gamma\}^{T}[S]\{\gamma\}+\left\{\chi^{\prime}\right\}^{T}\left[D_{0}\right]\left\{\chi^{\prime}\right\}+D_{t} \theta^{2}\right) d x= \\
\sum_{k=1}^{N} \frac{1}{2} \int\left(\left\{u^{\prime \prime}\right\}^{T}\left[D_{l k}\right]\left\{u^{\prime \prime}\right\}+\{\gamma\}^{T}\left[S_{k}\right]\{\gamma\}+\left\{\chi^{\prime}\right\}^{T}\left[D_{0 k}\right]\left\{\chi^{\prime}\right\}+D_{t k} \theta^{2}\right) d x,
\end{array}
$$


with

$$
\{u\}=\{v, w, \psi\}^{T}, \quad\{\chi\}=\left\{\chi_{y}, \chi_{z}, \theta_{B}\right\}^{T}, \quad\{\gamma\}=\left\{\gamma_{y}, \gamma_{z}, \theta_{S}\right\}^{T},
$$

and where $\left[D_{0 k}\right],\left[D_{l k}\right]$ and $\left[S_{k}\right]$ are the stiffness parameters of each equivalent beam substructure in the global reference system $x, y, z ; D_{t}$ and $D_{t k}$ are the torsional stiffness of the equivalent beam and the $k$-th sub-structure, respectively. These matrices are computed starting from the stiffness values in the local reference system $\eta, \zeta$ ( $\eta$ horizontal axis and $\zeta$ vertical axis)

$$
\left[D_{0}^{\eta, \zeta}\right]_{k}=\left[\begin{array}{lll}
D_{0 k} & 0 & 0 \\
0 & 0 & 0 \\
0 & 0 & 0
\end{array}\right], \quad\left[D_{l}^{\eta, \zeta}\right]_{k}=\left[\begin{array}{ccc}
D_{l k} & 0 & 0 \\
0 & 0 & 0 \\
0 & 0 & 0
\end{array}\right], \quad\left[S^{\eta, \zeta}\right]_{k}=\left[\begin{array}{ccc}
S_{k} & 0 & 0 \\
0 & 0 & 0 \\
0 & 0 & 0
\end{array}\right],
$$

and then changing the orientation and location of the lateral load-resisting sub-system by the transformation

$$
\left[X_{k}\right]=[T]_{k}^{T}\left[X^{\eta-\zeta}\right]_{k}[T]_{K} \quad \text { with }[T]_{k}=\left[\begin{array}{lll}
\cos \alpha_{k} & -\sin \alpha_{k} & r_{k \eta} \\
\sin \alpha_{k} & \cos \alpha_{k} & r_{k \zeta} \\
0 & 0 & 1
\end{array}\right] \quad k=1, \ldots, N,
$$

where $X$ can be $D_{0}, D_{l}$ or $S, \alpha_{k}$ is the angle between $\eta$ and $y$, and $r_{k \eta}$ and $r_{k \zeta}$ are the coordinates of the origin of the system $(\eta, \zeta)$ in the reference system $(x, y)$.

Solving Equation (31), the following relations are obtained

$$
\begin{aligned}
{[S] } & =\pi^{2}[B][C]^{-1}[B][C]^{-1}[B] \\
{\left[D_{0}\right] } & =[B][C]^{-1}[B]\left([I] \frac{1}{l_{0}^{2}}[B]^{-1}[C]\right)^{-1} \\
{\left[D_{l}\right] } & =[A]-[B][C]^{-1}[B] \\
D_{t} & =\sum_{k=1}^{N} D_{t k}
\end{aligned}
$$

where

$$
\begin{aligned}
{[A] } & =\sum_{k=1}^{N}\left(\left([I]+\frac{\pi^{2}}{l_{0}^{2}}\left[D_{0 k}\right]\left[S_{k}\right]^{-1}\right)^{-1}\left[D_{0 k}\right]+\left[D_{l k}\right]\right) \\
{[B] } & =\sum_{k=1}^{N}\left([I]+\frac{\pi^{2}}{l_{0}^{2}}\left[D_{0 k}\right]\left[S_{k}\right]^{-1}\right)^{-1}\left[D_{0 k}\right]\left[S_{k}\right]^{-1}\left([I]+\frac{\pi^{2}}{l_{0}^{2}}\left[D_{0 k}\right]\left[S_{k}\right]^{-1}\right)^{-1}\left[D_{0 k}\right] \\
{[C] } & =\sum_{k=1}^{N} \pi^{4}\left([I]+\frac{\pi^{2}}{l_{0}^{2}}\left[D_{0 k}\right]\left[S_{k}\right]^{-1}\right)^{-1}\left[D_{0 k}\right]\left[S_{k}\right]^{-1} \\
& \times\left([I]+\frac{\pi^{2}}{l_{0}^{2}}\left[D_{0 k}\right]\left[S_{k}\right]^{-1}\right)^{-1}\left[D_{0 k}\right]\left[S_{k}\right]^{-1}\left([I]+\frac{\pi^{2}}{l_{0}^{2}}\left[D_{0 k}\right]\left[S_{k}\right]^{-1}\right)^{-1}\left[D_{0 k}\right],
\end{aligned}
$$

Approximate values for $l_{0}$ are suggested when vibration analyses are of interest. For example, $l_{0}=2 \mathrm{H}, l_{0}=2 / 3 \mathrm{H}, l_{0}=2 / 5 \mathrm{H}$ can be assumed for modeling the first, second and third vibration mode, respectively.

\subsubsection{Modal Analysis}

Natural frequencies and associated mode shapes can be found solving the following eigenvalues and eigenvectors problem $[13,14]$

$$
\left[\left(\frac{H^{4}}{\mu_{B i}^{2}}\left[D_{0}\right]^{-1}+\frac{H^{2}}{\mu_{S i}^{2}}[S]^{-1}\right)^{-1}+\frac{\mu_{B i}^{2}}{H^{4}}\left[D_{l}\right]+\frac{\mu_{S i}^{2}}{H^{2}}[G]\right]\left\{\begin{array}{c}
v_{0 m} \\
w_{0 m} \\
\psi_{0 m}
\end{array}\right\}=\omega_{m i}^{2} m[M]\left\{\begin{array}{c}
v_{0 m} \\
w_{0 m} \\
\psi_{0 m}
\end{array}\right\},
$$


where

$$
[M]=\left[\begin{array}{lll}
1 & 0 & z_{m} \\
0 & 1 & -y_{m} \\
z_{m} & -y_{m} & \frac{\Theta}{m}+y_{m}^{2}+z_{m}^{2}
\end{array}\right], \quad[G]=\left[\begin{array}{lll}
0 & 0 & 0 \\
0 & 0 & 0 \\
0 & 0 & D_{t}
\end{array}\right],
$$

where $H$ is the equivalent beam height, $m$ is the mass per unit length, $\Theta$ is the polar moment of mass, $y_{m}$ and $z_{m}$ are the coordinates of the centroid. The values of $\mu_{B i}$ and $\mu_{S i}$ are respectively 3.52 and $0.5 \pi$ for the first vibration mode, 22.03 and $1.5 \pi$ for the second vibration mode and 61.7 and $1.25 \pi$ for the third vibration mode. The polar moment of mass is given by

$$
\Theta=\int_{A} \mu r^{2} d A,
$$

where $A$ is the region occupied by the generic building plan and $\mu$ is the mass per unit area. Assuming uniform mass distribution $\mu$ is constant, giving

$$
\Theta=\mu\left(I_{r}+I_{S}\right)
$$

where $I_{r}$ and $I_{s}$ are moments of inertia about $A$ principal axes.

\subsubsection{Torsional Stiffness}

When dealing with torsion, it is well-known that two stiffnesses may be considered: the classical De Saitnt-Venant torsion stiffness and the one associated with the section warping. The latest is implicit in the contribution given by $\left[D_{0}\right]$ and $\left[D_{l}\right]$, while the first one, represented by $D_{t}$ in Equation (42) need to be estimated. The following espression for $D_{t}$ is proposed in [15] when $w$ walls and $f$ frames and/or coupled beams are the considered sub-structures

$$
D_{t}=\sum_{k=1}^{w} G J_{k}+\sum_{h=1}^{f}\left(\left(S_{i}\right)_{y}\left(z_{i}-z_{C R}\right)^{2}+\left(S_{i}\right)_{z}\left(y_{i}-y_{C R}\right)^{2}\right),
$$

where $J_{k}$ is the torsional constant of the $k$-th wall and $\left(S_{i}\right)_{y}$ and $\left(S_{i}\right)_{z}$ are the shear stiffnesses of the $h$-th frame or coupled-beam having $y-z$ centroind coordinates equal to $y_{i}$ and $z_{i}$, with $y_{S C}$ and $z_{S C}$ being the coordinates of the stiffness center. Furthermore, the finding in [15] suggest using the effective shear stiffness, $S_{e}$, in place of the shear stiffness, $S$, as follows

$$
s_{e}=s_{f} S \quad \text { with } \quad s_{f}=\sqrt{\frac{(4 H)^{2} 0.313 D_{0}}{(4 H)^{2} 0.313 D_{0}+H^{4} S}} .
$$

The values of $y_{S C}$ and $z_{S C}$ can be estimated by

$$
y_{S C}=\frac{\sum_{i=1}^{w+f} f_{z, i}^{2} y_{i}}{\sum_{i=1}^{w+f} f_{z, i}^{2}}, \quad z_{S C}=\frac{\sum_{i=1}^{w+f} f_{y, i}^{2} z_{i}}{\sum_{i=1}^{w+f} f_{y, i}^{2}},
$$

where $f_{y, i}$ and $f_{z, i}$ are the frequencies in $y$ and $z$ direction of the wall and frame, that can be estimated with

$$
f=\sqrt{f_{b}^{2}+\frac{f_{g}^{2} f_{s^{\prime}}^{2}}{f_{g}^{2}+f_{s^{\prime}}^{2}}}
$$

where $f_{s^{\prime}}, f_{g}$ and $f_{b}$ are the frequencies considering only shear stiffness, global bending stiffness and local bending stiffness, respectively, given by 


$$
\begin{aligned}
f_{s^{\prime}}^{2} & =\frac{1}{(4 H)^{2}} \frac{r_{f}^{2} S}{m} \\
f_{g}^{2} & =\frac{0.313}{H^{4}} \frac{r_{f}^{2} D_{0}}{m} \\
f_{b}^{2} & =\frac{0.313}{H^{4}} \frac{r_{f}^{2} D_{l}}{m},
\end{aligned}
$$

with $r_{f}$ a factor related to the mass distribution.

\subsection{Estimation of Parameters and Genetic Algorithms}

The mechanical characteristics of the e-TBM described in Section 2.1 are calibrated minimizing a suitable function of $n m$ natural frequencies and $n d$ static displacements of the e-TBM and the e-SBM in Section 2.2 that has general expression:

$$
f\left(D_{1}, \ldots, D_{m}\right)=\sum_{i=0}^{n m} w_{i}\left|1-\frac{\omega_{i}^{e-T B M}}{\omega_{i}^{e-S B M}}\right|+\sum_{j=0}^{n d} w_{j}\left|1-\frac{u_{j}^{e-T B M}}{u_{j}^{e-S B M}}\right|,
$$

where $D_{d}, d=1, \ldots, n_{d v}$, are the $n_{d v}$ e-TBM design variables (e.g., mechanical parameters such as cross-section area, second moments, bending, shear and torsional stifnesses); $\omega_{i}^{e-T B M}$ and $\omega_{i}^{e-S B M}, i=1, \ldots, n m$, are the e-TBM and e-SBM natural frequencies; $u_{j}^{e-T B M}$ and $u_{j}^{e-S B M}, j=1, \ldots, n d$, are the e-TBM and e-SBM static response displacements; $w_{i}$ and $w_{j}$ are suitable weights to drive the solution on the desired target response parameters. At each step of the minimization procedure, a check on the modal shapes is performed in order to match both natural frequencies and mode shapes of the e-SBM.

Genetic algorithms [16] are chosen to minimize the function in Equation (53). This choice is usually done when the optimization problem cannot be solved using classical algorithms, for example because of the discontinuous, not derivable or stochastic objective functions. Classical minimizing algorithms were not successful in the case study that will be presented in this paper because of the significant influence of the initial design variable values. Sensitivity analysis was also performed to have information both on the influence of the variation of the design parameters on the quantities of interest and on the presence of local minima of Equation (53). The genetic algorithms were successful to overcome the problem due to their inherent feature to randomly search in the solution domain and to easily follow decreasing values of the objective function. The classic genetic algorithm can be summarized as follows [17]:

1. generation of a random set of values for the design variables (initial population);

2. evaluation of the objective function and selection of the best solutions;

3. generation of a new population of hybrid solutions by means of genetic operators (cross-over and mutation);

4. iterative repetition of points 2 . and 3. with this population;

5. termination of the algorithm when a specified condition is reached (e.g., convergence criteria, maximum number of generations, time limit).

A crucial point to find the optimal solution is to give a wide range for the initial population, which is related to the initial domain of the design variables.

\section{Results}

\subsection{Case Study Tall Building}

Figure 1 shows three views of the tall building used to demonstrate the effectiveness of the proposed approach. The building has a square plan with a side of $30.1 \mathrm{~m}$, overall height equal to $179.4 \mathrm{~m}$ and $3.9 \mathrm{~m}$ constant inter-story height for a total of 46 floors. The structural system consists of 16 steel frames, 8 for each direction, having $4.3 \mathrm{~m}$ bay length. Moreover, 
the four external frames have a bracing system. Structural steel, S235, has been considered, with elastic modulus $E=210,000 \mathrm{MPa}$. Column and beam sections are HD400 $\times 463$ and IPE360, respectively. Table 1 summarizes the geometrical properties of the used sections (values are not shown when not used in the analysis).

a

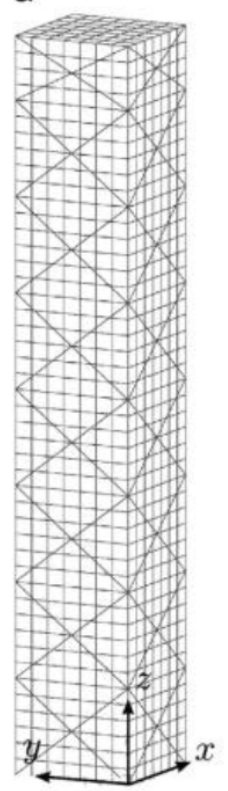

$b$

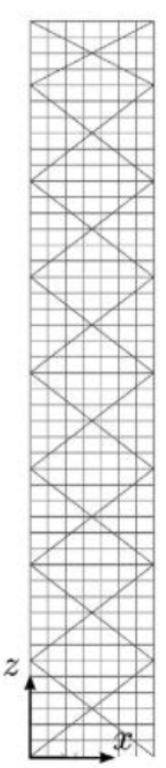

C

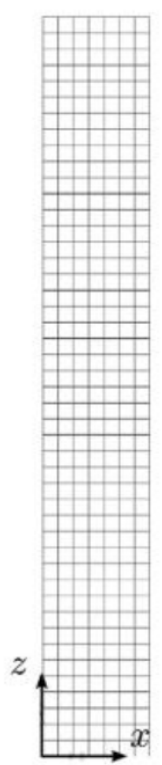

Figure 1. The case study: $3 \mathrm{~d}$ view (a), an external frame (b) and an internal frame (c).

Table 1. Geometrical properties of the frame sections.

\begin{tabular}{cccc}
\hline Section & $\begin{array}{c}\boldsymbol{A} \\
{\left[\boldsymbol{m}^{\mathbf{2}}\right]}\end{array}$ & $\begin{array}{c}\boldsymbol{I}_{\boldsymbol{S}} \text { (Strong Axis) } \\
{\left[\boldsymbol{m}^{\mathbf{4}}\right]}\end{array}$ & $\begin{array}{c}\boldsymbol{I}_{\boldsymbol{w}} \text { (Weak Axis) } \\
{\left[\boldsymbol{m}^{\mathbf{4}}\right]}\end{array}$ \\
\hline HD400 $\times 463$ & $5.88 \times 10^{-2}$ & $1.797 \times 10^{-3}$ & $6.703 \times 10^{-4}$ \\
IPE360 & - & $1.552 \times 10^{-4}$ & - \\
\hline
\end{tabular}

Tubular square sections with side $0.4 \mathrm{~m}$ and thickness $0.05 \mathrm{~m}$ are used for the bracing system with the following mass per unit length and polar moment of mass

$$
\begin{aligned}
& m=155640 \mathrm{~kg} / \mathrm{m} \\
& \Theta=\frac{m}{12}\left(a^{2}+b^{2}\right)=2.350 \cdot 10^{1} 0^{7} \mathrm{~kg} \mathrm{~m}^{2} / \mathrm{m} .
\end{aligned}
$$

\subsection{Sub-Structures' Stifness Parameters}

The following sub-structure's stiffness parameters are obtained using the approach proposed in Section 2.2:

-Internal frame in the $x$ direction

$$
\begin{aligned}
& D_{l}^{i f x}=\sum_{i=0}^{7} E I_{s}^{H D}=3.019 \cdot 10^{9} \mathrm{~N} \mathrm{~m}^{2} \\
& D_{0}^{i f x}=\sum_{i=0}^{7} E A_{c, i}^{H D} c_{i}^{2}=9.589 \cdot 10^{12} \mathrm{~N} \mathrm{~m}^{2}
\end{aligned}
$$




$$
\begin{aligned}
& S_{b}^{i f x}=\sum_{i=0}^{7} \frac{12 E I_{s}^{I P E 360}}{l_{i} h}=1.632 \cdot 10^{8} \mathrm{~N} \\
& S_{c}^{i f x}=\sum_{i=0}^{7} \frac{12 E I_{s}^{H D}}{h^{2}}=2.382 \cdot 10^{9} \mathrm{~N} \\
& S^{i f x}=\left(\left(S_{b}^{i f x}\right)^{-1}+\left(S_{c}^{i f x}\right)^{-1}\right)^{-1}=1.63 \cdot 10^{8} \mathrm{~N} .
\end{aligned}
$$

-Internal frame in the $y$ direction

$$
\begin{aligned}
& D_{l}^{i f y}=\sum_{i=0}^{7} E I_{w}^{H D}=1.126 \cdot 10^{9} \mathrm{~N} \mathrm{~m}^{2} \\
& D_{0}^{i f y}=\sum_{i=0}^{7} E A_{c, i}^{H D} c_{i}^{2}=9.589 \cdot 10^{12} \mathrm{~N} \mathrm{~m}^{2} \\
& S_{b}^{i f y}=\sum_{i=0}^{7} \frac{12 E I_{s}^{I P E 360}}{l_{i} h}=1.632 \cdot 10^{8} \mathrm{~N} \\
& S_{c}^{i f y}=\sum_{i=0}^{7} \frac{12 E I_{w}^{H D}}{h^{2}}=8.884 \cdot 10^{9} \mathrm{~N} \\
& S^{i f y}=\left(\left(S_{b}^{i f y}\right)^{-1}+\left(S_{c}^{i f y}\right)^{-1}\right)^{-1}=1.379 \cdot 10^{8} \mathrm{~N} .
\end{aligned}
$$

-External frame in the $x$ direction

The external frames in the $x$ direction have a bracing system (Figure 1). In this case, the bending stiffness $D_{0}$ is the same of Equation (57), while the shear stiffness is computed using Equation (26). Furthermore, since the topmost part of the bracing has smaller dimensions (Figure 2), the weighted mean for the length $d_{m}$ and the vertical height $h_{m}$ are used in place of $d$ and $h$ in (26).

$$
h_{m}=\frac{7 \cdot 23.4+15.6}{8}=22.425 \mathrm{~m}, \quad d_{m}=\frac{7 \cdot 38.13+33.9}{8}=37.598 \mathrm{~m} .
$$

Therefore, the values assumed for the external frame in the $x$ direction are the following:

$$
\begin{aligned}
D_{l}^{e f x} & =\sum_{i=0}^{7} E I_{s}^{H D}=3.019 \cdot 10^{9} \mathrm{~N} \mathrm{~m}^{2} \\
D_{0}^{e f x} & =\sum_{i=0}^{7} E A_{c, i}^{H D} c_{i}^{2}=9.589 \cdot 10^{12} \mathrm{~N} \mathrm{~m}^{2} \\
S_{b}^{i f x} & =\sum_{i=0}^{7} \frac{12 E I_{s}^{I P E 360}}{l_{i} h}=1.632 \cdot 10^{8} \mathrm{~N} . \\
S_{c}^{i f x} & =\sum_{i=0}^{7} \frac{12 E I_{s}^{H D}}{h^{2}}=2.382 \cdot 10^{9} \mathrm{~N} \\
S^{i f x} & =\left(\left(S_{b}^{i f x}\right)^{-1}+\left(S_{c}^{i f x}\right)^{-1}\right)^{-1}=1.632 \cdot 10^{8} \mathrm{~N} \\
S^{t} & =\frac{E h_{m} L^{2} A_{d}}{d_{m}^{3}}=1.124 \cdot 10^{10} \mathrm{~N} \\
S^{e f x} & =S^{i f x}+S^{t}=1.139 \cdot 10^{10} \mathrm{~N} .
\end{aligned}
$$


- External frame in $y$ direction

$$
\begin{aligned}
D_{l}^{e f y} & =\sum_{i=0}^{7} E I_{w}^{H D}=1.126 \cdot 10^{9} \mathrm{~N} \mathrm{~m}^{2} \\
D_{0}^{e f y} & =\sum_{i=0}^{7} E A_{c, i}^{H D} c_{i}^{2}=9.589 \cdot 10^{12} \mathrm{~N} \mathrm{~m}^{2} \\
S_{b}^{i f y} & =\sum_{i=0}^{7} \frac{12 E I_{s}^{I P E 360}}{l_{i} h}=1.632 \cdot 10^{8} \mathrm{~N} \\
S_{c}^{i f y} & =\sum_{i=0}^{7} \frac{12 E I_{w}^{H D}}{h^{2}}=8.884 \cdot 10^{9} \mathrm{~N} \\
S^{i f y} & =\left(\left(S_{b}^{i f y}\right)^{-1}+\left(S_{c}^{i f y}\right)^{-1}\right)^{-1}=1.379 \cdot 10^{8} \mathrm{~N} \\
S^{t} & =\frac{E h_{m} L^{2} A_{d}}{d_{m}^{3}}=1.124 \cdot 10^{10} \mathrm{~N} \\
S^{e f y} & =S^{i f y}+S^{t}=1.138 \cdot 10^{10} \mathrm{~N} .
\end{aligned}
$$
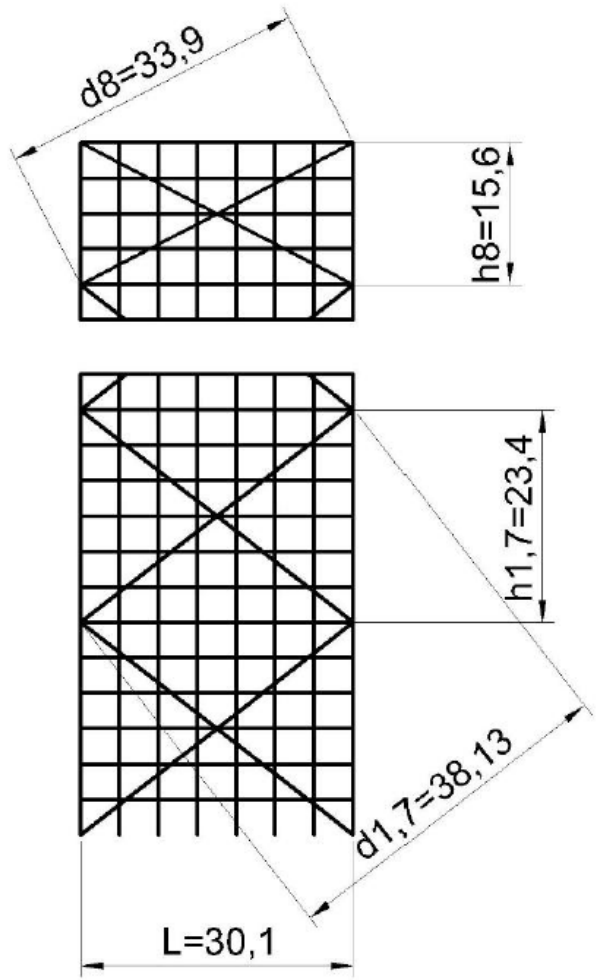

Figure 2. Bracing on the external frame in $x$ direction.

3.3. Torsional Stiffness, Natural Frequencies and Static Displacements of The e-SBM

The torsional stiffness can be computed using Equation (46)

$$
\begin{aligned}
D_{t} & =\sum_{h=1}^{f}\left(\left(S_{i}\right)_{y}\left(z_{i}-z_{C R}\right)^{2}+\left(S_{i}\right)_{z}\left(y_{i}-y_{C R}\right)^{2}\right)= \\
& =2 \cdot\left(S^{i f x}+S^{i f y}\right) \cdot\left(2.15^{2}+6.45^{2}+10.75^{2}\right)+2 \cdot\left(S^{e f x}+S^{e f y}\right) \cdot 15.05^{2}=1.041 \cdot 10^{13} \mathrm{~N} \mathrm{~m}^{2} .
\end{aligned}
$$

The solution of the e-SBM is obtained by first computing the stiffness parameters solving Equation (31), and secondly, evaluating the natural frequencies solving the problem 
in (42). Table 2 summarizes the obtained results in terms of natural periods and compares these values with those computed using a detailed SAP2000 FE model.

Table 2. Natural periods between the e-SBM and FE models.

\begin{tabular}{cccc}
\hline Mode & $\begin{array}{c}T^{e-S B M} \\
{[s]}\end{array}$ & $\begin{array}{c}T^{F E M} \\
{[s]}\end{array}$ & $\begin{array}{c}\text { Error } \\
{[\%]}\end{array}$ \\
\hline 1 & 4.491 & 4.832 & 7.596 \\
2 & 4.457 & 4.779 & 7.222 \\
3 & 1.142 & 1.017 & -10.946 \\
4 & 1.119 & 0.989 & -11.618 \\
5 & 1.118 & 0.984 & -11.987 \\
6 & 0.624 & 0.464 & -25.604 \\
7 & 0.576 & 0.462 & -19.810 \\
8 & 0.537 & 0.307 & -42.761 \\
9 & 0.526 & 0.169 & -67.799 \\
\hline
\end{tabular}

The first two modes are in the $y$ and $x$ direction (Figure 1), while the third mode shape is torsional. For these three modes, the error from the detailed FE model solution is below $11 \%$. The torsional model has a satisfactory estimate given the inclusion of the warping contribution in the e-SBM. These results suggested that the sub-structure approach for the considered case study can be effectively used as a reference for the first five modal frequencies that will be used as quantities of interest in Equation (53). It is worth noting that, in this case, the effect of the bracing system on the external frames is significant: neglecting this term in the sub-structures would result in a first natural period rising to $9.135 \mathrm{~s}$, more than double the actual value.

Beside modal frequencies, the novel calibration procedure described in Section 2.3 requires knowledge of the static response of the e-SBM. In this case study the response displacements to uniformly distributed loads over the height, $z$, of the building are used. In particular, the displacements at the top floor in the $x$ and $y$ directions, $u$ and $v$, obtained, respectively, for a static load in the $x$ and $y$ directions are computed using the modal analysis results, in terms of $n m$ natural periods, $T_{k}$, and modal shapes, $\phi_{k}(z), k=1, \ldots, n m$.

When a beam of length $H$ is affected by a load $F(z, t)$, the $k$-th elementary oscillator is ruled by the following equation

$$
\ddot{q}_{k}+2 v_{k} \omega_{k} \dot{q}_{k}+\omega_{k}^{2} q_{k}=\frac{f_{k}(t)}{m_{k}}
$$

with

$$
\omega_{k}=\frac{2 \pi}{T_{k}}, \quad m_{k}=\int_{0}^{H} \mu(z) \phi_{k}(z)^{2} d z
$$

and

$$
f_{k}(t)=\int_{0}^{H} F(z, t) \phi_{k}(z) d z .
$$

In this case study, a pseudo-static uniformly distributed load is considered, than can be represented by

$$
F(z, t)=F_{0} \sin \left(\frac{2 \pi}{T} t\right) \quad \text { with } T \gg T_{k} .
$$

In this case, the steady-state response is given by

$$
v(z)=\sum_{k=1}^{\infty} q_{k} \phi_{k}(z)
$$

with

$$
q_{k}=\frac{f_{k}}{m_{k} \omega_{k}}=\frac{F_{0} \int_{0}^{H} \phi_{k}(z) d z}{\omega_{k} \mu \int_{0}^{H} \phi_{k}(z)^{2} d z},
$$


where the summation is stopped after a finite number of terms. In this case study, the first $n m=6$ modes and $F_{0}=100 \mathrm{kN} / \mathrm{m}$ are assumed giving the following top floor, $z=H$, static displacements

$$
\begin{aligned}
& u=0.467 \mathrm{~m} \\
& v=0.478 \mathrm{~m} .
\end{aligned}
$$

It is worth noting that these displacements differ less than $3.5 \%$ from the corresponding values computed using the detailed FE model $\left(u_{F E M}=0.484 \mathrm{~m}, v_{F E M}=0.493 \mathrm{~m}\right)$.

\subsection{Calibration of The e-TBM}

The last step of the proposed procedure is the calibration of the mechanical parameters of the 3D Timoshenko beam model, e-TBM, using the optimization procedure presented in Section 2.3. Using the target response parameters of the e-SBM computed in Section 3.3. In particular, the results in Table 2 suggested using five natural frequencies together with the two static displacements in the $x$ and $y$ directions at the beam free end. The function in Equation (53) becomes:

$$
\begin{aligned}
f\left(A, A_{s, x} \cdot A_{s, y}, I_{x}, I_{y}, I_{t}\right) & =w_{1}\left|1-\frac{\omega_{1}^{e-T B M}}{\omega_{1}^{e-S B M}}\right|+w_{2}\left|1-\frac{\omega_{2}^{e-T B M}}{\omega_{2}^{e-S B M}}\right|+w_{3}\left|1-\frac{\omega_{3}^{e-T B M}}{\omega_{3}^{e-S B M}}\right|+ \\
& +w_{4}\left|1-\frac{\omega_{4}^{e-T B M}}{\omega_{4}^{e-S B M}}\right|+w_{5}\left|1-\frac{\omega_{5}^{e-T B M}}{\omega_{5}^{e-S B M}}\right|+w_{6}\left|1-\frac{u^{e-T B M}}{u^{e-S B M}}\right|+w_{7}\left|1-\frac{v^{e-T B M}}{v^{e-S B M}}\right|,
\end{aligned}
$$

where the e-TBM response parameters are evaluated using a numerical model and the assumed design variables are

- $\quad$ cross-section area, $A$;

- $\quad$ shear area in $x$ and $y$ directions, $A_{s, x}$ and $A_{s, y}$;

- $\quad$ second inertia moments around $x$ and $y, I_{x}$ and $I_{y}$;

- $\quad$ torsional stiffness, $I_{t}$.

and the assumed weights, to make the convergence easier and to drive the solution to better approximate the first three natural frequencies and the two static displacements, are summarized in Table 3.

Table 3. Weights used in Equation (90).

\begin{tabular}{cccccccc}
\hline $\mathbf{k}$ & $\mathbf{1}$ & $\mathbf{2}$ & $\mathbf{3}$ & $\mathbf{4}$ & $\mathbf{5}$ & $\mathbf{6}$ & $\mathbf{7}$ \\
\hline$w_{k}$ & 1.00 & 1.00 & 0.67 & 0.33 & 0.33 & 1.00 & 1.00 \\
\hline
\end{tabular}

Assuming the following data

- $\quad L=179.4 \mathrm{~m}$ (building height);

- $M=2.792 \times 10^{7} \mathrm{~kg}$ (total mass of the building);

- number of elements of the FE model equal to the number of floors, $N_{F E}=46$;

- $E=2.1 \times 10^{11} \mathrm{~N} / \mathrm{mm}^{2}$ (Young's modulus);

- $G=8.75 \times 10^{10} \mathrm{~N} / \mathrm{m}^{2}$ (Shear modulus).

and using genetic algorithms to minimize the function in (90), the design variables result as follows: $A=36.7125 \mathrm{~m}^{2}, A_{s, x}=0.1628 \mathrm{~m}^{2}, A_{s, y}=0.1652 \mathrm{~m}^{2}, I_{x}=168.1814 \mathrm{~m}^{4}$, $I_{y}=173.9372 \mathrm{~m}^{4}, I_{t}=6.5456 \mathrm{~m}^{4}$.

Table 4 compares the response of the obtained e-TBM with the e-SBM and the detailed FE model. The calibration makes the e-TBM response almost identical to the e-SBM. This is confirmed by the relative difference between the e-TBM and FE model response (eF), which is very close to the corresponding values in the last column in Table 2. It is worth noting that the minimum of Equation (90) is very close to zero, i.e., 0.1194 , and a sensitivity analysis suggests that a global minimum is found. Indeed, Figure 3 shows the sensitivity 
analysis for couples of design variables, keeping the remaining four at the optimal values. In particular Figure $3 \mathrm{a}-\mathrm{c}$ show the variation of the objective function with the second inertia moments, $I_{x}$ and $I_{y}$, the shear areas, $A_{s, x}$ and $A_{s, y}$, the cross-section area and torsional stiffness, $A$ and $I_{t}$, respectively. The red dot in the three sub-figures indicates the value of the function in (90) at the optimal design parameters. Another interesting feature of this case study is that the weights used in Equation (90) seem to have no effect given the perfect match of the chosen response parameters.

Table 4. Natural frequencies of the three models and relative errors: between e-TBM and e-SBM (eS); between e-TBM and FE model (eF).

\begin{tabular}{cccccc}
\hline Parameter & e-SBM & e-TBM & eS [\%] & FE Model & eF [\%] \\
\hline$\omega_{1}$ & 1.3991 & 1.4111 & 0.859 & 1.3003 & 8.520 \\
$\omega_{2}$ & 1.4097 & 1.4256 & 1.130 & 1.3146 & 8.434 \\
$\omega_{3}$ & 5.5019 & 5.5019 & 0.000 & 6.1787 & -10.946 \\
$\omega_{4}$ & 5.6150 & 5.6152 & 0.004 & 6.3512 & -11.614 \\
$\omega_{5}$ & 5.6200 & 5.6200 & 0.000 & 6.3859 & -11.986 \\
$u$ & 0.4675 & 0.4675 & 0.000 & 0.4836 & -3.329 \\
$v$ & 0.4780 & 0.4780 & 0.000 & 0.4933 & -3.102 \\
\hline
\end{tabular}

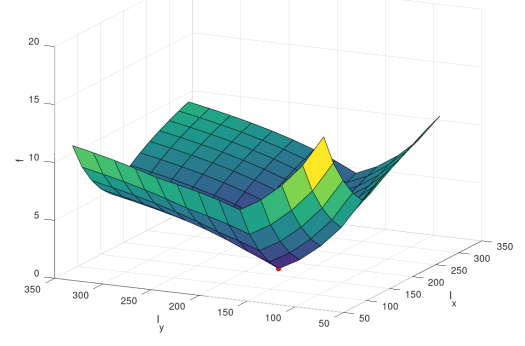

(a)

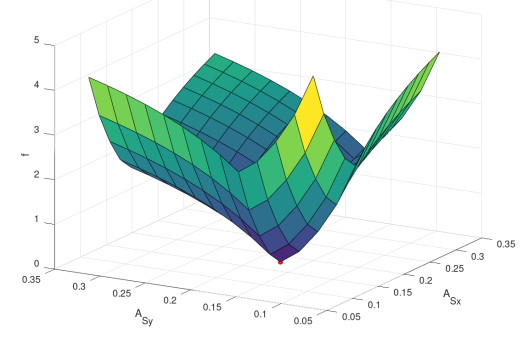

(b)

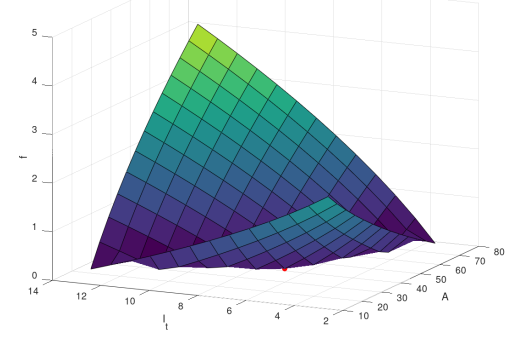

(c)

Figure 3. Sensitivity analysis and minimum at the optimal design parameters: second inertia moments, $I_{x}$ and $I_{y}$, (a), shear areas, $A_{s, x}$ and $A_{s, y},(\mathbf{b})$ and cross-section area and torsional stiffness, $A$ and $I_{t}(\mathbf{c})$.

The ability of the e-TBM to describe the tall building dynamic structural response can be also verified with time domain seismic analysis. To this aim, spectrum-compatible acceleration time histories are generated using the method proposed in [18] and the corresponding response time series is computed by direct integration using Newmark's method. The following parameters were chosen for the design spectrum of Eurocode 8 [19]: $S=1.15$, $a_{g}=0.35 \cdot 9.81 \mathrm{~m} / \mathrm{s}^{2}, \beta=2.5, T_{B}=0.2 \mathrm{~s}, T_{C}=0.6 \mathrm{~s}, T_{D}=2 \mathrm{~s}, k_{1}=1, k_{2}=2, \eta=1$.

A total of 10 acceleration time histories are generated with $30 \mathrm{~s}$ duration, $10 \mathrm{~s}$ stationary interval between $4 \mathrm{~s}$ and $14 \mathrm{~s}$, and sampling rate, $f_{s}=0.005 \mathrm{~s}$. Figure 4 compares the target spectrum (continuous line) and the mean response spectrum of the generated acceleration time series (dotted line).

Figures 5 and 6 compare, respectively, the top level displacement and the base shear time histories of the detailed FE model (left panels) and the e-TBM (right panels) for one acceleration time series in the $x$ direction. 


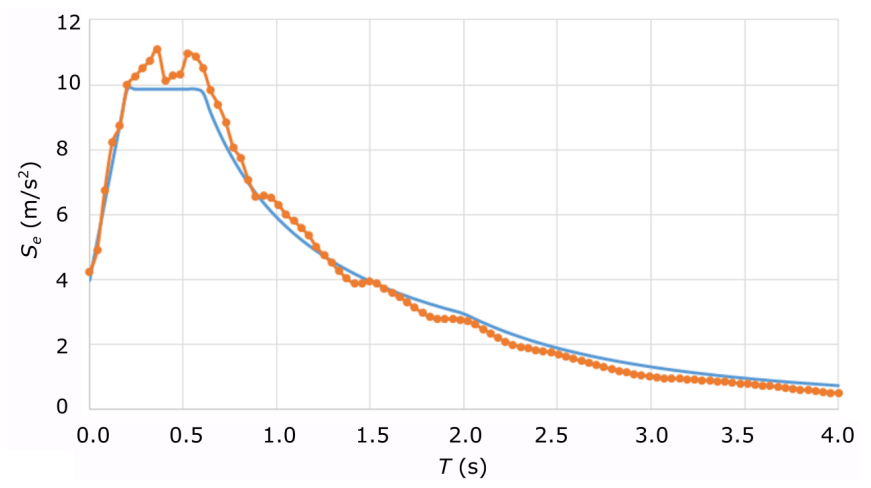

Figure 4. Comparison between the target spectrum (blue continuous line) and the mean spectrum of the 10 generated time series (red dotted line).

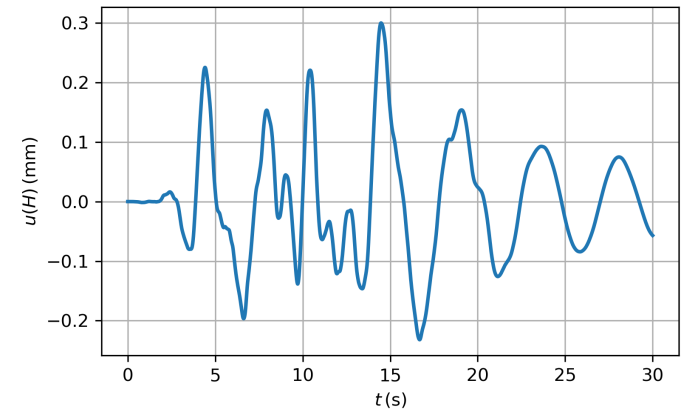

(a)

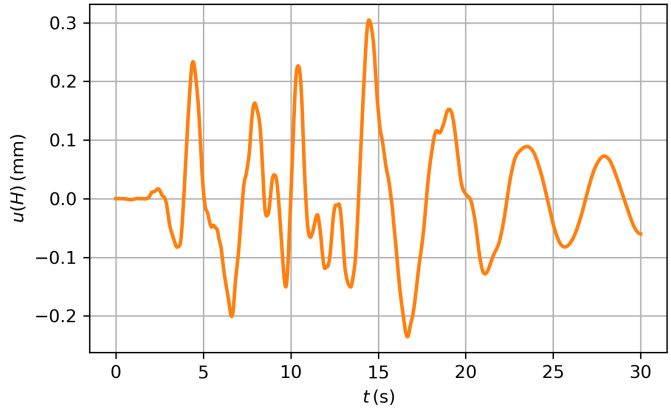

(b)

Figure 5. Top-level displacement in $x$ direction in the detailed FE model (a) and in the e-TBM (b).

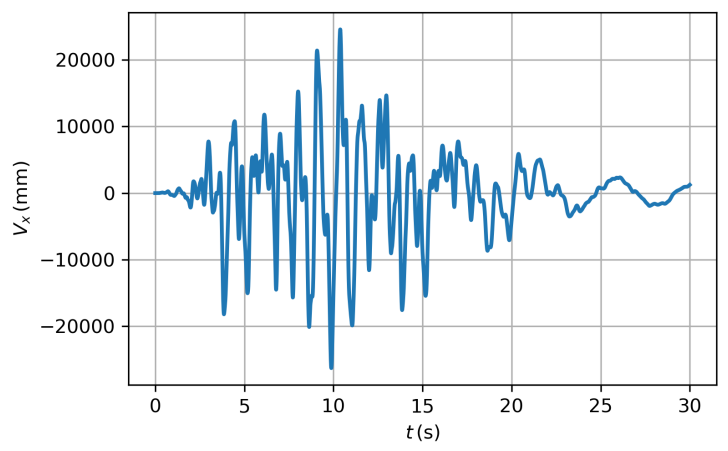

(a)

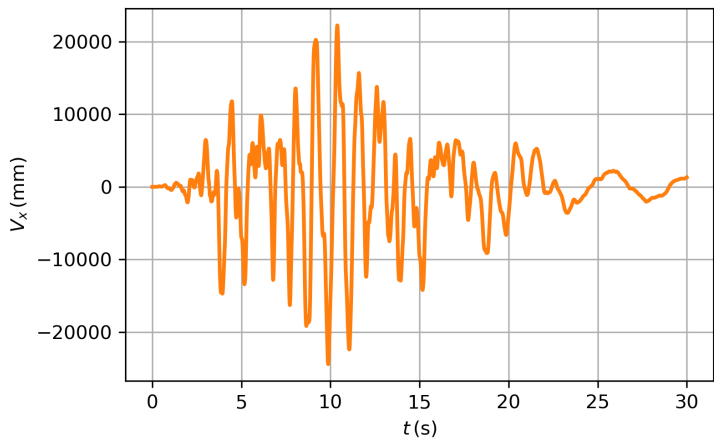

(b)

Figure 6. Base shear in $x$ direction in the full F.E.M. model (a) and in the Timoshenko beam model (b).

Table 5 compares the average response results for the ten seismic acceleration time series in the two directions $x$ and $y$. In particular, the average values of the maxima, $\mu_{\max }$ the mean values, $\mu_{\text {ave }}$ and the standard deviation values, $\mu_{\sigma}$ are estimated. The comparison shows good results for displacements with differences below $4 \%$, while a slight loss of accuracy is experienced by the base shear with differences of the order of $20 \%$. The main advantage of the proposed approach is the paramount reduction of computational cost once the mechanical parameters are calibrated. Indeed, the ratio between time to complete the $10 \mathrm{~s}$ seismic analysis, described above, with the detailed FE model and the reduced order e-TBM is higher than 300 when using a personal laptop with an Intel Core i5 processor. In particular, the Newmark direct integration of 10 acceleration time histories in the $x$ 
and $y$ direction using the e-TBM and the complete FE model (i.e., with all the beam and column elements in Figure 1) needed $104 \mathrm{~s}$ and $10 \mathrm{~h}$, respectively. This result confirms the effectiveness of the proposed procedure to perform both global response structural optimization strategies and reliability analyses.

Table 5. Response statistics for the e-TBM and the FE model top displacements $(u(H)$ and $v(H))$ and base shear $\left(V_{x}\right.$ and $\left.V_{y}\right)$.

\begin{tabular}{|c|c|c|c|c|c|c|c|}
\hline \multirow{2}{*}{ Seismic Direction } & \multirow{2}{*}{ Response } & \multicolumn{2}{|c|}{$\mu_{\max }$} & \multicolumn{2}{|c|}{$\mu_{\text {ave }}$} & \multicolumn{2}{|c|}{$\mu_{\sigma}$} \\
\hline & & FE Model & e-TBM & FE Model & e-TBM & FE Model & e-TBM \\
\hline$x$ & $u(H)$ & 0.318 & 0.320 & 0.000 & 0.000 & 0.105 & 0.105 \\
\hline$x$ & $V_{x}$ & 27410 & 34622 & -14.38 & -12.4 & 6687.9 & 6704.3 \\
\hline$y$ & $v(H)$ & 0.318 & 0.317 & 0.000 & 0.001 & 0.106 & 0.107 \\
\hline$y$ & $V_{y}$ & 27549 & 31598 & -14.34 & -13.8 & 6835.5 & 6748.9 \\
\hline
\end{tabular}

\section{Discussion and Perspectives}

The work presented in this paper proposed a novel two-step approach to calibrate a reduced-order 3D Timoshenko beam model to accurately describe the structural response of complex tall buildings affected by stochastic loads without the need for time-consuming and expensive detailed finite element models. The novelty of the paper consists of merging two equivalent beam models proposed in the literature in order to enhance the advantages and to overcome the drawbacks of each of the two. The first step consisted of computing the mechanical characteristics of an equivalent sandwich beam model using the substructures approach, first proposed by Potzta and Kollar, and evaluating both the static and modal response (natural frequencies and mode shapes). These response parameters were used in the second step to calibrate the mechanical features of the Timoshenko beam model recently proposed by these Authors, which is able to describe the coupled bending, shear and torsional behavior. The calibration was obtained by a suitable optimization genetic algorithm that can be driven to better describe the response parameters of interest using appropriate weights in the function to be minimized. The proposed procedure improves the equivalent sandwich beam model, whose dynamic response solution needs specific parameters depending on the mode shape of interest. On the contrary, once the equivalent Timoshenko beam is calibrated, an exact closed-form solution is obtained for all the modal response.

A tall building with a square plan but different stiffness to horizontal loads in two directions was used as a case study. The main results, validated using a detailed finite element model, can be summarized as follows:

1. the equivalent sandwich beam modal response differs by less than $12 \%$ from the detailed numerical model in the first five natural frequencies;

2. the modal response of the calibrated equivalent Timoshenko beam perfectly matches the corresponding sandwich beam model and therefore has the same accuracy in describing the actual tall building response;

3. seismic response maximum and average displacements estimated using direct time integration differ less than $4 \%$ from the detailed model;

4. computational time ratio for $10 \mathrm{~s}$ of seismic dynamic analysis between the detailed numerical model and the reduced-order equivalent Timoshenko beam model is higher than 300 .

The obtained results confirm the effectiveness of the proposed procedure to calibrate equivalent Timoshenko beam models without the need for preliminary time-consuming complex numerical finite element models to describe the tall building structural response. This is of paramount importance when performing structural optimization strategies for the global response in the context of reliability analysis. The main immediate perspective of this work is the validation of the proposed novel calibration procedure for complex irregular tall buildings (non-symmetric). 
Author Contributions: Conceptualization, F.C., S.F., V.G. and M.G.; methodology, F.C., V.G. and M.G.; software, F.C. and S.F.; validation, F.C., S.F., V.G. and M.G.; data curation, F.C. and S.F.; writing-original draft preparation, F.C. and M.G.; writing—review and editing, F.C., V.G. and M.G.; All authors have read and agreed to the published version of the manuscript.

Funding: This research received no external funding.

Institutional Review Board Statement: Not applicable.

Informed Consent Statement: Not applicable.

Data Availability Statement: The data presented in this study are available on request from the corresponding author.

Conflicts of Interest: The authors declare no conflict of interest.

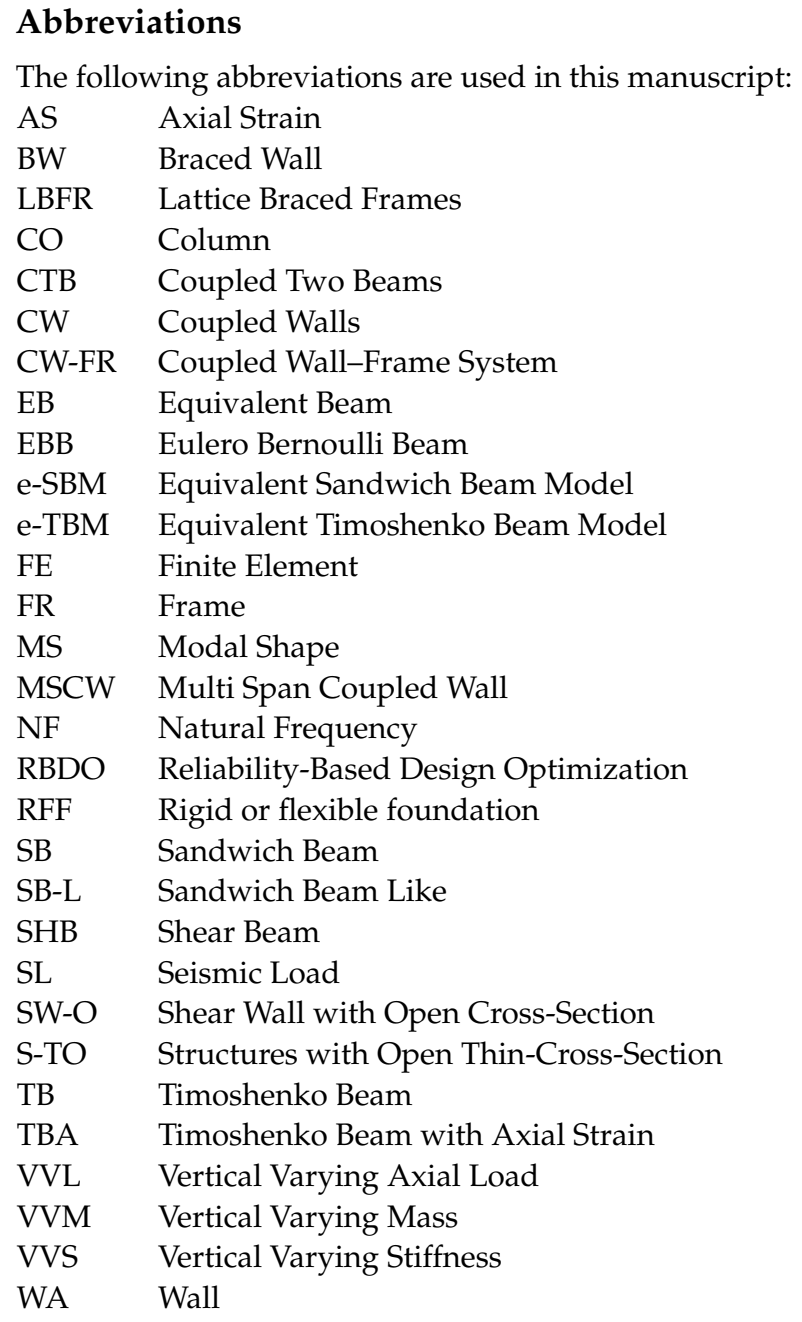

\section{Appendix A. Summay of the Equivalent Beam Models}

The main equivalent beam models reported in the literature are summarized in Table A1. Refer to Section 4 for the list of abbreviations.

The first column presents the main authors and the years when models were proposed. The second column lists the bracing system that can be described by the model. The third column reports the equivalent beam model used: Eulero Bernulli beam, EBB (i.e., bending stiffness only); shear stiffness only beam, SHB; Timoshenko beam, TB (i.e., shear and bending stiffness in series); Timoshenko beam with axial strain, TBA, coupled two beams, CTB (i.e., bending beam coupled with shear a beam); sandwich beam, SB (i.e., bending beam coupled with a Timoshenko beam). When bending and torsion coupling is considered 
(i.e., asymmetric buildings) a check mark is placed in the fourth column and the torsional stiffness used is described in the third column between parenthesis: $G J_{t}$ and $E I_{\omega}$ are the De Saint-Venant and secondary stiffesses, respectively. When a symmetry plane is needed it is indicated in the note column. A check mark is placed in the columns 5 to 9 when the model describes, respectively, stiffness vertical variations, axial strain, natural frequencies, mode shapes and seismic loads. Additional features are summarized in the note column.

Table A1. Summary of the main equivalent beam models reported in the literature.

\begin{tabular}{|c|c|c|c|c|c|c|c|c|c|}
\hline Model & Bracing & EB & Coupling & VVS & AS & NFs & MSs & SL & Note \\
\hline Skattum (1971) [20] & $\mathrm{CW}$ & SB-L & & & $\checkmark$ & $\checkmark$ & $\checkmark$ & & \\
\hline Heidebrecht et al. (1973) [21] & WAs, FRs & СТВ & & & & $\checkmark$ & & & $\begin{array}{l}\text { Static } \\
\text { analysis }\end{array}$ \\
\hline Rosman (1974) [22] & WA, FR & СТВ & & & & $\checkmark$ & & & Buckling \\
\hline Rosmann (1981) [23] & $\mathrm{CO}, \mathrm{WA}, \mathrm{BW}$ & $\begin{array}{c}\mathrm{EBB} \\
\left(E I_{\omega}\right)\end{array}$ & $\checkmark$ & & & $\checkmark$ & $\checkmark$ & & Buckling \\
\hline Rutenberg (1975) [24] & CW & $\mathrm{SB}$ & & & $\checkmark$ & $\checkmark$ & & & \\
\hline Rutenberg et al. $(1977,1978)[25,26]$ & FR, WA & $\begin{array}{l}\text { CTB } \\
\left(G J_{t},\right. \\
\left.E I_{\omega}\right)\end{array}$ & $\checkmark$ & & & $\checkmark$ & $\checkmark$ & & 1-sym plane \\
\hline Mukherjee and Coull (1977) [27] & SW-O & $\begin{array}{l}\mathrm{EBB} \\
\left(G J_{t},\right. \\
\left.E I_{\omega}\right)\end{array}$ & & & & $\checkmark$ & $\checkmark$ & & RFF \\
\hline Reinhorn et al. $(1977,1979)[28,29]$ & FR, WA & $\begin{array}{l}\mathrm{CTB} \\
\left(G J_{t},\right. \\
\left.E I_{\omega}\right)\end{array}$ & $\checkmark$ & & & $\checkmark$ & $\checkmark$ & $\checkmark$ & 1-sym plane \\
\hline Basu et al. (1982) [30,31] & CW-FR & & & & & $\checkmark$ & $\checkmark$ & $\checkmark$ & $\begin{array}{l}\text { Graphic } \\
\text { solution }\end{array}$ \\
\hline Basu (1983) [32] & $\mathrm{CW}$ & & & & & $\checkmark$ & $\checkmark$ & $\checkmark$ & $\begin{array}{l}\text { Graphic } \\
\text { solution }\end{array}$ \\
\hline Basu et al. (1984) [33] & CW-FR & СТВ & & & & $\checkmark$ & $\checkmark$ & $\checkmark$ & $\begin{array}{l}\text { Graphic } \\
\text { solution }\end{array}$ \\
\hline Balendra et al. (1984) [34] & FR, WA & $\begin{array}{l}\text { CTB } \\
\left(G J_{t},\right. \\
\left.E I_{\omega}\right)\end{array}$ & $\checkmark$ & $\checkmark$ & & $\checkmark$ & $\checkmark$ & & $\begin{array}{l}\text { 1-sym plane, } \\
\text { RFF }\end{array}$ \\
\hline Stafford Smith et al. $(1986,1991)[35-37]$ & $\begin{array}{c}\text { FR, LBFR, WA, } \\
\text { CW }\end{array}$ & SB & & & $\checkmark$ & $\checkmark$ & & $\checkmark$ & $\begin{array}{c}\text { Graphic } \\
\text { solution, } \\
\text { first two NFs }\end{array}$ \\
\hline Wang et al. (2000)[38] & FR, WA & $\begin{array}{c}\mathrm{SB}\left(G J_{t},\right. \\
\left.E I_{\omega}\right)\end{array}$ & $\checkmark$ & & $\checkmark$ & $\checkmark$ & & & $\begin{array}{l}\text { 1-sym plane, } \\
\text { first two NFs }\end{array}$ \\
\hline Ng and Kuang (2000) [39] & FR, WA & $\begin{array}{l}\text { CTB } \\
\left(G J_{t \prime}\right. \\
\left.E I_{\omega}\right)\end{array}$ & $\checkmark$ & & & $\checkmark$ & $\checkmark$ & & \\
\hline Kuang and Ng (2001) [40] & WA & $\begin{array}{l}\mathrm{EBB} \\
\left(E I_{\omega}\right)\end{array}$ & $\checkmark$ & & & $\checkmark$ & $\checkmark$ & & \\
\hline Kuang and Ng (2004) [41] & FR, WA, CW & $\begin{array}{l}\text { CTB } \\
\left(G J_{t},\right. \\
\left.E I_{\omega}\right)\end{array}$ & $\checkmark$ & & & $\checkmark$ & $\checkmark$ & & \\
\hline Kuang and $\mathrm{Ng}$ (2009) [42] & FR & $\begin{array}{l}\text { SHB } \\
\left(G J_{t}\right)\end{array}$ & $\checkmark$ & & & $\checkmark$ & $\checkmark$ & & \\
\hline Li et al. (2000) [43] & WA & EBB & & $\checkmark$ & $\checkmark$ & $\checkmark$ & $\checkmark$ & & $\begin{array}{l}\text { VVM, VVL, } \\
\text { axial Load }\end{array}$ \\
\hline Rahgozar et al. (2004) [44] & FR, WA & TB & & $\checkmark$ & & $\checkmark$ & $\checkmark$ & & VVM \\
\hline Swaddiwudhipong et al. $(1989,2001,2002)[45-47]$ & FR, WA & TBA & & & $\checkmark$ & $\checkmark$ & $\checkmark$ & & $\begin{array}{l}\text { Axial force } \\
\text { on frames } \\
\text { Static }\end{array}$ \\
\hline Zalka $(2000,2001,2013)[15,48,49]$ & $\begin{array}{c}\text { FR, LBFR, WA, } \\
\text { CW }\end{array}$ & $\begin{array}{c}\mathrm{SB}\left(G J_{t},\right. \\
\left.E I_{\omega}\right)\end{array}$ & $\checkmark$ & & $\checkmark$ & $\checkmark$ & & & $\begin{array}{l}\text { analysis, } \\
\text { buckling, } \\
\text { first NF }\end{array}$ \\
\hline Potzta, Kollár, Tarján $(2002,2003,2004)$ [11,14,50] & $\begin{array}{c}\text { FR, LBFR, WA, } \\
\text { CW }\end{array}$ & $\begin{array}{c}\mathrm{SB}\left(G J_{t},\right. \\
\left.E I_{\omega}\right)\end{array}$ & $\checkmark$ & $\checkmark$ & $\checkmark$ & $\checkmark$ & $\checkmark$ & $\checkmark$ & Buckling \\
\hline Kaviani et al. (2008) [51] & $\begin{array}{c}\text { FR, LBFR, WA, } \\
\text { CW }\end{array}$ & $\begin{array}{c}\mathrm{SB}\left(G J_{t},\right. \\
\left.E I_{\omega}\right)\end{array}$ & $\checkmark$ & $\checkmark$ & $\checkmark$ & $\checkmark$ & & & VVM \\
\hline Rafezy et al. (2007) [52] & FR & $\mathrm{SB}\left(G J_{t}\right)$ & $\checkmark$ & $\checkmark$ & & $\checkmark$ & $\checkmark$ & & \\
\hline Rafezy and Howson (2008) [53] & FR, WA & $\begin{array}{l}\text { CTB } \\
\left(G J_{t}\right. \\
\left.E I_{\omega}\right)\end{array}$ & $\checkmark$ & $\checkmark$ & & $\checkmark$ & $\checkmark$ & & \\
\hline Miranda et al.(2005) [54-56] & FR, WA & СТВ & & $\checkmark$ & & $\checkmark$ & $\checkmark$ & $\checkmark$ & $\begin{array}{c}\text { Time history } \\
\text { analysis, } \\
\text { floor acc. }\end{array}$ \\
\hline Georgoussis (2006) [57] & FR, WA, CW & SB & & & $\checkmark$ & $\checkmark$ & $\checkmark$ & $\checkmark$ & \\
\hline Meftah et al. (2007) [58] & WA, S-TO & $\begin{array}{l}\text { EBB } \\
\left(G J_{t},\right. \\
\left.E I_{\omega}\right)\end{array}$ & $\checkmark$ & & & $\checkmark$ & $\checkmark$ & $\checkmark$ & \\
\hline Meftah and Tounsi (2008) [59] & WA, S-TO & $\begin{array}{l}\mathrm{EBB} \\
\left(E I_{\omega}\right)\end{array}$ & $\checkmark$ & & & $\checkmark$ & $\checkmark$ & & \\
\hline Bozdogan and Ozturk (2007) [60] & MSCW & SB & & $\checkmark$ & $\checkmark$ & $\checkmark$ & $\checkmark$ & $\checkmark$ & $\begin{array}{l}\text { Discrete } \\
\text { solution }\end{array}$ \\
\hline
\end{tabular}


Table A1. Cont.

\begin{tabular}{|c|c|c|c|c|c|c|c|c|c|}
\hline Model & Bracing & EB & Coupling & VVS & AS & NFs & MSs & SL & Note \\
\hline Bozdogan (2009) [61] & FR, WA & SB & & $\checkmark$ & $\checkmark$ & $\checkmark$ & $\checkmark$ & $\checkmark$ & $\begin{array}{l}\text { Discrete } \\
\text { solution } \\
\text { Discrete }\end{array}$ \\
\hline Bozdogan (2011) [62] & FR, WA & SB & & $\checkmark$ & $\checkmark$ & $\checkmark$ & $\checkmark$ & $\checkmark$ & $\begin{array}{l}\text { solution,wall } \\
\text { shear strain }\end{array}$ \\
\hline Bozdogan and Ozturk (2012) [63] & FR, WA & $\begin{array}{l}\text { CTB } \\
\left(G J_{t},\right. \\
\left.E I_{\omega}\right)\end{array}$ & $\checkmark$ & $\checkmark$ & & $\checkmark$ & $\checkmark$ & $\checkmark$ & $\begin{array}{l}\text { Discrete } \\
\text { solution }\end{array}$ \\
\hline Cluni et al. $(2013,2020)[8,64]$ & $\begin{array}{c}\text { FR, LBFR, WA, } \\
\text { CW }\end{array}$ & $\mathrm{TB}$ & $\checkmark$ & & & $\checkmark$ & $\checkmark$ & $\checkmark$ & $\begin{array}{l}\text { Closed form } \\
\text { solution }\end{array}$ \\
\hline Piccardo et al. $(2015,2016,2019)[7,65,66]$ & FR, WA & TB & $\checkmark$ & & $\checkmark$ & $\checkmark$ & $\checkmark$ & & \\
\hline Luongo et al. $(2020,2021)[9,10]$ & FR & $\mathrm{TB}$ & $\checkmark$ & & $\checkmark$ & $\checkmark$ & $\checkmark$ & & \\
\hline Greco et al. (2020) [67] & FR & SHB & & $\checkmark$ & & $\checkmark$ & $\checkmark$ & & \\
\hline
\end{tabular}

\section{References}

1. Howson, W.P. Global analysis-back to the future. Struct. Eng. 2006, 84, 18-21.

2. Spence, S.; Gioffrè, M. Efficient algorithms for the reliability optimization of tall buildings. J. Wind Eng. Ind. Aerodyn. 2011, 99, 691-699. [CrossRef]

3. Spence, S.M.; Gioffrè, M. Large scale reliability-based design optimization of wind excited tall buildings. Probabil. Eng. Mech. 2012, 28, 206-215. [CrossRef]

4. Spence, S.M.; Gioffrè, M.; Kareem, A. An efficient framework for the reliability-based design optimization of large-scale uncertain and stochastic linear systems. Probabil. Eng. Mech. 2016, 44, 174-182. [CrossRef]

5. Bartoli, G.; Cluni, F.; Gusella, V.; Procino, L. Dynamics of cable under wind action: Wind tunnel experimental analysis. J. Wind Eng. Ind. Aerodyn. 2006, 94, 259-273. [CrossRef]

6. Gioffrè, M.; Gusella, V. Peak response of a nonlinear beam. J. Eng. Mech. 2007, 133, 963-969. [CrossRef]

7. Piccardo, G.; Tubino, F.; Luongo, A. Equivalent Timoshenko linear beam model for the static and dynamic analysis of tower buildings. Appl. Math. Model. 2019, 71,77-95. [CrossRef]

8. Gioffrè, M.; Cluni, F.; Gusella, V. Characterization of an Equivalent Coupled Flexural-Torsional Beam Model for the Analysis of Tall Buildings under Stochastic Actions. J. Struct. Eng. 2020, 146. [CrossRef]

9. D'Annibale, F.; Ferretti, M.; Luongo, A. Static and dynamic responses of micro-structured beams. Appl. Sci. 2020, $10,6836$. [CrossRef]

10. Luongo, A.; D'Annibale, F.; Ferretti, M. Shear and flexural factors for static analysis of homogenized beam models of planar frames. Eng. Struct. 2021, 228, 111440. [CrossRef]

11. Potzta, G.; Kollar, L. Analysis of building structures by replacement sandwich beams. Int. J. Solids Struct. 2003, 40, 535-553. [CrossRef]

12. Kollár, L.P. Flexural-torsional buckling of open section composite columns with shear deformation. Int. J. Solids Struct. 2001, 38, 7525-7541. [CrossRef]

13. Kollár, L.P. Flexural-torsional vibration of open section composite beams with shear deformation. Int. J. Solids Struct. 2001, 38, 7543-7558. [CrossRef]

14. Potzta, G. Approximate analysis of building structures subjected to earthquakes. Ph.D. Thesis, Technical University of Budapest, Budapest, Hungary, 2002.

15. Zalka, K.A. Structural Analysis of Regular Multi-Storey Buildings; CRC Press: Boca Raton, FL, USA, 2013.

16. Mitchell, M. An Introduction to Genetic Algorithms; MIT Press: Cambridge, MA, USA, 1996.

17. Whitley, D. A genetic algorithm tutorial. Stat. Comput. 1994, 4, 65-85. [CrossRef]

18. Cacciola, P. A stochastic approach for generating spectrum compatible fully nonstationary earthquakes. Comput. Struct. 2010, 88, 889-901; Cited by 65. [CrossRef]

19. EN 1998-1: Eurocode 8: Design of Structures for Earthquake Resistance; BSi: Brussels, Belgium, 2004.

20. Skattum, K.S. Dynamic analysis of coupled shear walls and sandwich beams. Ph.D. Thesis, California Institute of Technology, Pasadena, CA, USA, 1971.

21. Heidebrecht, A.C.; Smith, B.S. Approximate analysis of tall wall-frame structures. J. Struct. Div. 1973, 99, 199-221. [CrossRef]

22. Rosman, R. Stability and dynamics of shear-wall frame structures. Build. Sci. 1974, 9, 55-63. [CrossRef]

23. Rosman, R. Buckling and vibrations of spatial building structures. Eng. Struct. 1981, 3, 194-202. [CrossRef]

24. Rutenberg, A. Approximate natural frequencies for coupled shear walls. Earthq. Eng. Struct. Dyn. 1975, 4, 95-100. [CrossRef]

25. Rutenberg, A.; Tso, W.; Heidebrecht, A. Dynamic properties of asymmetric wall-frame structures. Earthq. Eng. Struct. Dyn. 1977, 5, 41-51. [CrossRef]

26. Rutenberg, A.; Glück, J.; Reinhorn, A. On the dynamic properties of asymmetric wall-frame structures. Earthq. Eng. Struct. Dyn. 1978, 6, 317-320. [CrossRef]

27. Mukherjee, P.R.; Coull, A. Free vibrations of open-section shear walls. Earthq. Eng. Struct. Dyn. 1977, 5, 81-101. [CrossRef] 
28. Reinhorn, A.; Rutenberg, A.; Glück, J. Dynamic torsional coupling in asymmetric building structures. Build. Environ. 1977, 12, 251-261. [CrossRef]

29. Glück, J.; Reinhorn, A.; Rutenberg, A. Dynamic torsional coupling in tall building structures. Proc. Inst. Civ. Eng. 1979, 67, 411-424. [CrossRef]

30. Basu, A.K.; Dar, G.Q. Dynamic characteristics of coupled wall-frame systems. Earthq. Eng. Struct. Dyn. 1982, 10, 615-631. [CrossRef]

31. Basu, A.K.; Nagpal, A.K.; Nagar, A.K. Dynamic characteristics of frame-wall systems. J. Struct. Div. 1982, 108, 1201-1218. [CrossRef]

32. Basu, A.K. Seismic design charts for coupled shear walls. J. Struct. Eng. 1983, 109, 335-352. [CrossRef]

33. Basu, A.K.; Nagpal, A.K.; Kaul, S. Charts for seismic design of frame-wall systems. J. Struct. Eng. 1984, 110, 31-46. [CrossRef]

34. Balendra, T.; Swaddiwudhipong, S.; Quek, S.T.; Lee, S.L. Free vibration of asymmetric shear wall-frame buildings. Earthq. Eng. Struct. Dyn. 1984, 12, 629-650. [CrossRef]

35. Smith, B.S.; Crowe, E. Estimating periods of vibration of tall buildings. J. Struct. Eng. 1986, 112, 1005-1019. [CrossRef]

36. Smith, B.S.; Yoon, Y.S. Estimating seismic base shears of tall wall-frame buildings. J. Struct. Eng. 1991, 117, 3026-3041. [CrossRef]

37. Stafford Smith, B.; Coull, A. Tall Building Structures: Analysis and Design; Wiley: Hoboken, NJ, USA, 1991.

38. Wang, Y.; Arnaouti, C.; Guo, S. A simple approximate formulation for the first two frequencies of asymmetric wall-frame multi-storey building structures. J. Sound Vib. 2000, 236, 141-160. [CrossRef]

39. Ng, S.; Kuang, J.S. Triply coupled vibration of asymmetric wall-frame structures. J. Struct. Eng. 2000, 126, 982-987. [CrossRef]

40. Kuang, J.; Ng, S.C. Dynamic coupling of asymmetric shear wall structures: An analytical solution. Int. J. Solids Struct. 2001, 38, 8723-8733. [CrossRef]

41. Kuang, J.S.; Ng, S. Coupled vibration of tall building structures. Struct. Des. Tall Spec. Build. 2004, 13, 291-303. [CrossRef]

42. Kuang, J.S.; Ng, S.C. Lateral shear-St. Venant torsion coupled vibration of asymmetric-plan frame structures. Struct. Des. Tall Spec. Build. 2009, 18, 647-656. [CrossRef]

43. Li, Q.; Fang, J.; Jeary, A. Free vibration analysis of cantilevered tall structures under various axial loads. Eng. Struct. 2000, 22, 525-534. [CrossRef]

44. Rahgozar, R.; Safari, H.; Kaviani, P. Free vibration of tall buildings using Timoshenko beams with variable cross-section. WIT Trans. Built Environ. 2004, 73. [CrossRef]

45. Swaddiwudhipong, S.; Piriyakoontorn, S.; Lim, Y.B.; Lee, S.L. Analysis of tall buildings considering the effect of axial deformation by the Galerkin method. Comput. Struct. 1989, 32, 1363-1369. [CrossRef]

46. Swaddiwudhipong, S.; Lee, S.L.; Zhou, Q. Effect of axial deformation on vibration of tall buildings. Struct. Des. Tall Build. 2001, 10, 79-91. [CrossRef]

47. Swaddiwudhipong, S.; Sidji, S.S.; Lee, S.L. The effects of axial deformation and axial force on vibration characteristics of tall buildings. Struct. Des. Tall Build. 2002, 11, 309-328. [CrossRef]

48. Zalka, K. Global Structural Analysis of Buildings; CRC Press: Boca Raton, FL, USA, 2000.

49. Zalka, K. A simplified method for calculation of the natural frequencies of wall-frame buildings. Eng. Struct. 2001, 23, 1544-1555. [CrossRef]

50. Tarján, G.; Kollár, L.P. Approximate analysis of building structures with identical stories subjected to earthquakes. Int. J. Solids Struct. 2004, 41, 1411-1433. [CrossRef]

51. Kaviani, P.; Rahgozar, R.; Saffari, H. Approximate analysis of tall buildings using sandwich beam models with variable cross-section. Struct. Des. Tall Spec. Build. 2008, 17, 401-418. [CrossRef]

52. Rafezy, B.; Zare, A.; Howson, W.P. Coupled lateral-torsional frequencies of asymmetric, three-dimensional frame structures. Int. J. Solids Struct. 2007, 44, 128-144. [CrossRef]

53. Rafezy, B.; Howson, W.P. Vibration analysis of doubly asymmetric, three-dimensional structures comprising wall and frame assemblies with variable cross-section. J. Sound Vib. 2008, 318, 247-266. [CrossRef]

54. Miranda, E.; Taghavi, S. Approximate floor acceleration demands in multistory buildings. I: Formulation. J. Struct. Eng. 2005, 131, 203-211. [CrossRef]

55. Taghavi, S.; Miranda, E. Approximate floor acceleration demands in multistory buildings. II: Applications. J. Struct. Eng. 2005, 131, 212-220. [CrossRef]

56. Reinoso, E.; Miranda, E. Estimation of floor acceleration demands in high-rise buildings during earthquakes. Struct. Des. Tall Spec. Build. 2005, 14, 107-130. [CrossRef]

57. Georgoussis, G.K. A simple model for assessing periods of vibration and modal response quantities in symmetrical buildings. Struct. Des. Tall Spec. Build. 2006, 15, 139-151. [CrossRef]

58. Meftah, S.A.; Tounsi, A.; El Abbas, A.B. A simplified approach for seismic calculation of a tall building braced by shear walls and thin-walled open section structures. Eng. Struct. 2007, 29, 2576-2585. [CrossRef]

59. Meftah, S.A.; Tounsi, A. Vibration characteristics of tall buildings braced by shear walls and thin-walled open-section structures. Struct. Des. Tall Spec. Build. 2008, 17, 203-216. [CrossRef]

60. Bozdogan, K.B.; Öztürk, D. An Approximate Method for Free Vibration Analysis of Multi-Bay Coupled Shear Walls. Math. Comput. Appl. 2007, 12, 41-50. [CrossRef] 
61. Bozdogan, K.B. An approximate method for static and dynamic analyses of symmetric wall-frame buildings. Struct. Des. Tall Spec. Build. 2009, 18, 279-290. [CrossRef]

62. Bozdogan, K.B. A method for lateral static and dynamic analyses of wall-frame buildings using one dimensional finite element. Sci. Res. Essays 2011 , 6, 616-626.

63. Bozdogan, K.B.; Ozturk, D. Vibration analysis of asymmetric shear wall-frame structures using the transfer matrix method. J. Sci. Technol. Transact. B. Eng. 2012, 36, 1-12.

64. Cluni, F.; Gioffrè, M.; Gusella, V. Dynamic response of tall buildings to wind loads by reduced order equivalent shear-beam models. J. Wind Eng. Ind. Aerodyn. 2013, 123, 339-348. [CrossRef]

65. Piccardo, G.; Tubino, F.; Luongo, A. A shear-shear torsional beam model for nonlinear aeroelastic analysis of tower buildings. Z Für Angew. Math. Und Phys. 2015, 66, 1895-1913. [CrossRef]

66. Piccardo, G.; Tubino, F.; Luongo, A. Equivalent nonlinear beam model for the 3-D analysis of shear-type buildings: Application to aeroelastic instability. Int. J. Non-Linear Mech. 2016, 80, 52-65. [CrossRef]

67. Greco, A.; Fiore, I.; Occhipinti, G.; Caddemi, S.; Spina, D.; Caliò, I. An equivalent non-uniform beam-like model for dynamic analysis of multi-storey irregular buildings. Appl. Sci. 2020, 10, 3212. [CrossRef] 